\title{
Erratum to: Peroxiredoxins and sports: new insights on the antioxidative defense
}

\author{
Christian Brinkmann $^{1} \cdot$ Klara Brixius ${ }^{1}$
}

Published online: 19 June 2017

(C) The Physiological Society of Japan and Springer Japan KK 2017

\section{Erratum to: J Physiol Sci (2013) 63:1-5 DOI 10.1007/s12576-012-0237-4}

There are a few errors in the original publication of the article and the errors are corrected with this erratum.

On page 1, in the section "Peroxiredoxins as antioxidative proteins", the following sentences should read:

1. They make up approximately $0.1-1 \%$ of soluble proteins in the majority of human cells $[3,4]$ and constitute the third most abundant protein in the cytosol of erythrocytes [5].

2. Moreover, in addition to the enzymes GPX and CAT, they are involved in the decomposition of $\mathrm{H}_{2} \mathrm{O}_{2}$ to water $[8,9]$.
In Table 2,

1. ... the third column name should be "Subjects/ animals" rather than "Subjects".

2. ... in the fourth row, Subjects/animals of Richters et al. [23] should be read as "SOD2-knockout mice $(n=14)$ ".

On page 4, in the section "Effect of acute exercise on peroxiredoxins", the following sentence should read: "The fact that PRDX under increased oxidative stress overoxidizes in...".

The online version of the original article can be found under doi:10.1007/s12576-012-0237-4.

Christian Brinkmann

ch.brinkmann@gmx.net

1 Department of Molecular and Cellular Sport Medicine,

German Sport University Cologne, Am Sportpark

Müngersdorf 6, 50933 Cologne, Germany 